Claremont Colleges

Scholarship@ Claremont

All HMC Faculty Publications and Research

HMC Faculty Scholarship

5-1-1995

\title{
Visible Luminescence from Single Crystal-Silicon Quantum Wells
}

Peter N. Saeta

Harvey Mudd College

A. C. Gallagher

University of Colorado at Boulder

\section{Recommended Citation}

"Visible luminescence from single crystal-silicon quantum wells," P. N. Saeta and A. C. Gallagher, J. Appl. Phys. 77, 4639 (1995). doi: $10.1063 / 1.359430$

This Article is brought to you for free and open access by the HMC Faculty Scholarship at Scholarship @ Claremont. It has been accepted for inclusion in All HMC Faculty Publications and Research by an authorized administrator of Scholarship @ Claremont. For more information, please contact scholarship@cuc.claremont.edu. 


\section{AIP $\mid \begin{array}{ll}\text { soumalof } \\ \text { Applied Physics }\end{array}$}

\section{Visible luminescence from single crystalsilicon quantum wells}

P. N. Saeta and A. C. Gallagher

Citation: J. Appl. Phys. 77, 4639 (1995); doi: 10.1063/1.359430

View online: http://dx.doi.org/10.1063/1.359430

View Table of Contents: http://jap.aip.org/resource/1/JAPIAU/v77/i9

Published by the AIP Publishing LLC.

\section{Additional information on J. Appl. Phys.}

Journal Homepage: http://jap.aip.org/

Journal Information: http://jap.aip.org/about/about_the_journal

Top downloads: http://jap.aip.org/features/most_downloaded

Information for Authors: http://jap.aip.org/authors

\section{ADVERTISEMENT}

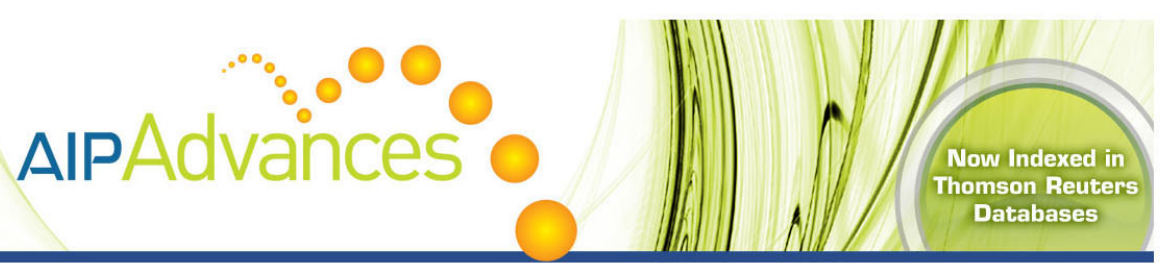

\section{Explore AIP's open access journal: Rapid publication \\ - Article-level metrics \\ - Post-publication rating and commenting}




\title{
Visible luminescence from single crystal-silicon quantum wells
}

\author{
P. N. Saeta ${ }^{a)}$ and A. C. Gallagher \\ JILA/NIST Qulantum Physics Division, Campus Box 440, University of Colorado, Boulder, Colorado \\ 80309-0440
}

(Received 14 November 1994; accepted for publication 24 January 1995)

\begin{abstract}
Single crystal-silicon quantum wells with $\mathrm{SiO}_{2}$ barriers have been grown from SIMOX silicon-on-insulator substrates. Photoluminescence in the red and near-infrared is observed for average well width $<8 \mathrm{~nm}$, with peak signal for $2-\mathrm{nm}$ average width. The luminescence spectrum is independent of well width for $\mathrm{SiO}_{2}$ barriers, but shifts $0.3 \mathrm{eV}$ to higher energy upon removal of the upper oxide layer with HF. Both results suggest the importance of radiation from surface states. (C) 1995 American Institute of Physics.
\end{abstract}

\section{INTRODUCTION}

The recent discovery of efficient photoluminescence from anodically etched porous silicon ${ }^{1}$ has generated tremen-. dous excitement for the prospect of integrated silicon electronics and optoelectronics. Several basic mechanisms have been advanced to explain the visible luminescence: quantum confinement, ${ }^{1}$ surface states ${ }^{2}$ amorphous $\mathrm{Si}^{3}{ }^{3}$ and siloxene. ${ }^{4}$ Strong evidence has emerged to rule out the siloxene and $a$-Si hypotheses, ${ }^{5,6}$ and to suggest that the luminescence arises from crystalline silicon structures in the porous silicon matrix. ${ }^{7}$ Whether radiative recombination takes place in the bulk or on the surface of quantum-confined silicon structures remains controversial. Furthermore, the problem of turning high photoluminescence to high electroluminescence efficiency needs to be solved. This study of a silicon quantum well structure addresses both issues.

The essentially inhomogeneous structure of porous silicon makes it difficult to identify the fraction of material responsible for efficient luminescence. This difficulty has motivated a search for more "model" silicon-based systems with well-characterized dimensions. Oxide-clad silicon quantum wells could have a number of advantages compared to porous silicon. These include the possibility of efficient electrical excitation, mechanical, and electrical robustness, and compatibility with conventional planar silicon processing technology. Valence- and conduction-band offsets in excess of $3 \mathrm{eV}$ (Ref. 8) create a type I well with excellent confinement. Polycrystalline silicon-on-oxide layers can be grown by vapor deposition and annealing, but grain boundaries cause excessive nonradiative recombination. We have instead grown oxide-clad crystal-silicon quantum wells by high-temperature oxidation of silicon-on-insulator substrates. This produces MOS device-quality flat $\mathrm{Si}_{/} \mathrm{SiO}_{2}$ interfaces with low trap density. ${ }^{9}$ Visible photoluminescence with a spectrum similar to the red component of porous silicon luminescence is observed for average well thicknesses less than $\sim 8 \mathrm{~nm}$.

\section{EXPERIMENT}

Single silicon quantum wells were fabricated from two kinds of SIMOX ${ }^{10}$ silicon-on-insulator wafers obtained from

${ }^{a j}$ Electronic mail: saeta@jila.colorado.edu
SOITEC, Inc. Standard wafers had an upper silicon layer thickness of $204.6 \mathrm{~nm}$ (3.0 nm peak-to-peak variation across a diameter) and a buried oxide thickness of $401.8 \mathrm{~nm}(4.6$ $\mathrm{nm})$. A special triple-implant/anneal wafer had a $205 \mathrm{~nm}$ silicon layer and $380 \mathrm{~nm}$ buried oxide layer, with slightly greater variation in layer thicknesses. The primary advantage of the triple-implant wafer was the absence of silicon islands in the buried oxide near the substrate. ${ }^{11}$ All wafers had (100) orientation.

The wafers were oxidized in dry $\mathrm{O}_{2}$ in a quartz tube furnace. Unless otherwise noted, the oxidation temperature was $1100^{\circ} \mathrm{C}$ and all processing was conducted at atmospheric pressure. For initial studies $1.5 \mathrm{~cm}$ square pieces were oxidized at uniform temperature. As the silicon layer thickness, $d$, approached $10 \mathrm{~nm}$, the sample was periodically removed and $d$ was determined from the reflection spectrum (see below). For later studies, we found it useful to prepare samples having a gradually tapered well thickness (typical tapers were $<1 \mathrm{~nm} / \mathrm{mm}$ ). This permitted us to measure the photoluminescence spectrum and efficiency vs $d$ after each process (oxidation, anneal, etc.), thereby separating the effects of layer thickness and surface chemistry. These samples were produced by performing the initial oxidation in a spatial temperature gradient (see Fig. 1). Samples were annealed at $1100^{\circ} \mathrm{C}$ in $\mathrm{Ar}$ for $>30 \mathrm{~min}$ at various stages of the oxidation to smooth the silicon-oxide interface. ${ }^{9,12}$ Such anneals were typically performed two or three times before the silicon layer thickness was reduced below $10 \mathrm{~nm}$.

\section{RESULTS}

Reflection spectra were taken over the range $200-800$ $\mathrm{nm}$ at $\sim 9^{\circ}$ incidence with a spectrophotometer. The beam size on the sample was approximately $1.5 \times 2 \mathrm{~mm}$. Spectra were corrected by comparison to a reference silica flat and then fitted to a three-layer model of the quantum well structure using the thin-film equations ${ }^{13}$ and bulk values for the index of refraction of $c$-Si (Ref. 14) and $a-\mathrm{SiO}_{2}$ (Ref. 15). For samples prepared from standard wafers, adequate fits were obtained only when the silicon layer was thick enough $(d \gtrsim 20 \mathrm{~nm})$ to hide the silicon islands. The triple-implant wafer yielded excellent fits, as illustrated in Fig. 1, which shows reflection spectra taken at several positions, $z$, along a tapered sample. The inset at the lower right of Fig. 1 shows $d(z)$ for this sample (the uncertainty in $z$ is $0.5 \mathrm{~mm}$ ). From 


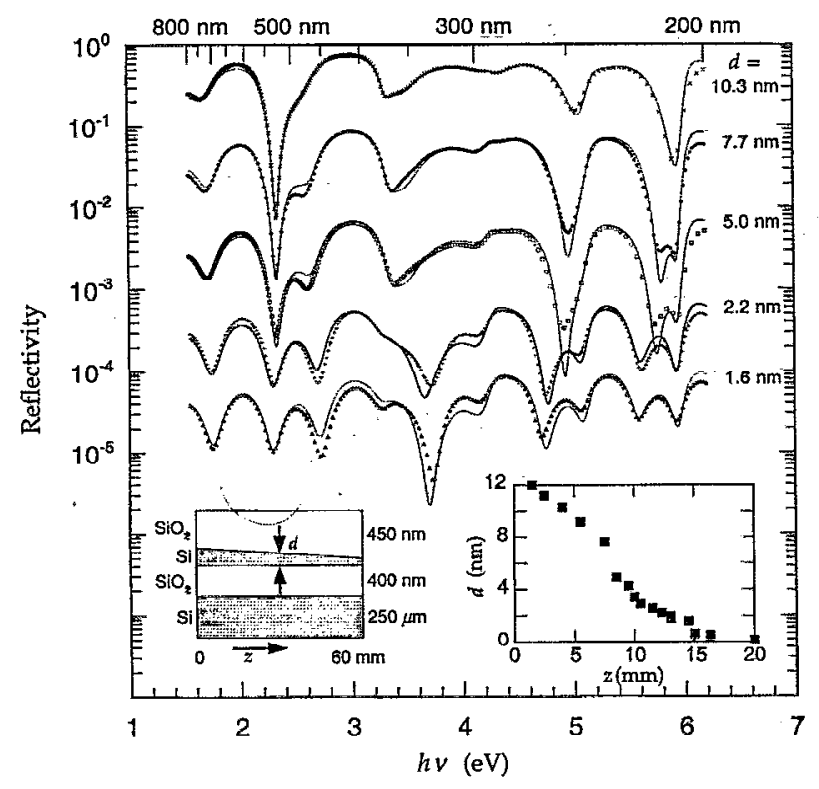

FIG. 1. Reflectivity spectra of a Si quantum well at several positions along the direction, $z$, of varying thickness (shown schematically in the left inset). The discrete symbols are data and successive spectra are offset by one order of magnitude for clarity. The smooth curves through the data are fits to a model of the three-layer structure that uses bulk values for the dielectric functions. The silicon layer thickness, $d$, deduced from the fit is indicated to the right of each spectrum. The thickness profile of this quantum well sample, $d(z)$, deduced from these fits is shown in the right inset.

the smooth curve, $d(z)$, we conclude that the reflection spectra and three-layer fits give accurate average values of $d .^{16}$

Further confirmation of the layer thickness and crystallinity was obtained from a cross-sectional TEM analysis of a sample prepared from standard SIMOX under uniform temperature conditions. The TEM photograph showed a $\sim 2-\mathrm{nm}-$ thick layer of approximately uniform thickness whose diffraction pattern indicated it was crystalline. The layer appeared segmented, but because the exposure and contrast of the image was poor it was impossible to determine whether the segmentation was real or caused by varying transverse thickness of the ion-milled sample. However, the ratio of the thickness to the in-plane width of the segments was $\sim 30$, suggesting that the geometry of the silicon layer was principally two-dimensional.

Room temperature $\mathrm{cw}$ luminescence spectra were taken at three different excitation wavelengths $(325,442$, and 488 $\mathrm{nm}$ ) using a spectrometer, blocking filters, and a cooled photomultiplier tube. Typical excitation conditions using the 325 $\mathrm{nm}$ line of a $\mathrm{HeCd}$ laser were $40^{\circ}$ incidence, TE polarization, $0.2 \mathrm{~mW}$, and an excited area of $\sim 0.2 \times 3 \mathrm{~mm}$. For $d \leqslant 8 \mathrm{~nm}$ a broad red luminescence peak was observed with a spectrum that was essentially independent of both excitation wavelength and layer thickness. Figure 2(a) shows luminescence spectra taken at different positions along a tapered sample; the luminescence peak has a Gaussian shape, with center at $1.66 \mathrm{eV}$ and FWHM of $0.20 \mathrm{eV}$, independent of sample thickness. This spectrum is similar to many reported in the literature for porous silicon and silicon nanocrystals. The uppermost trace represents the thickness giving maximum luminescence from this sample; successive spectra taken as the
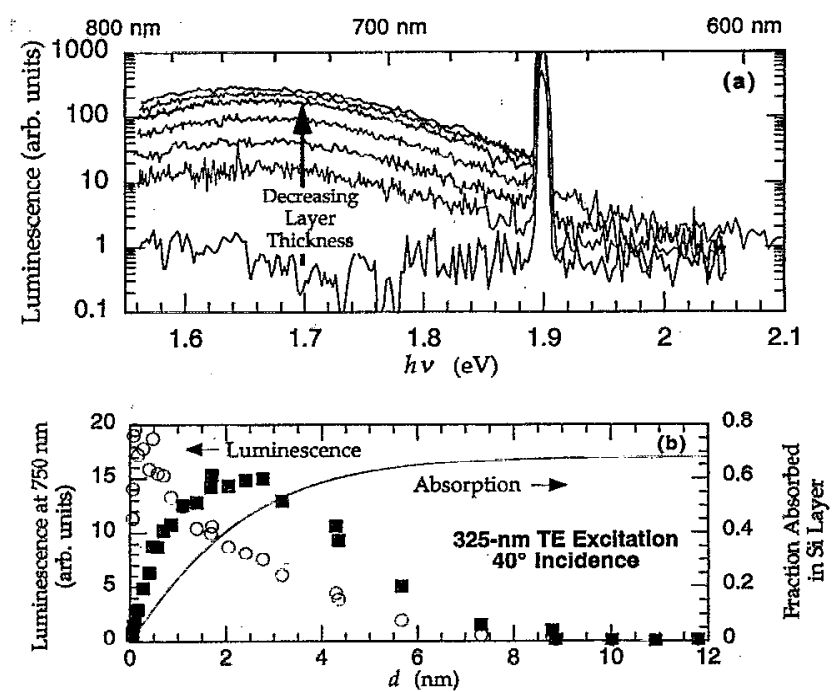

FIG. 2. (a) Corrected photoluminescence spectra taken at several layer thicknesses using $325 \mathrm{~nm}$ excitation. The red luminescence peak is wellfitted by a Gaussian with center at $1.66 \mathrm{eV}(747 \mathrm{~nm})$ and $0.20 \mathrm{eV}$ FWHM. (The large peak at $1.9 \mathrm{eV}$ is the second-order of the laser.) (b) The filled squares show the dependence of the peak luminescence signal at $750 \mathrm{~nm}$ on the mean silicon layer thickncss. The smooth curve shows the calculated fraction of the incident pump light absorbed in the thin silicon layer. The open circles are the ratio of luminescence to absorbed light.

layer thinned further (omitted for clarity) show decaying luminescence intensity. This sample had buried silicon islands, which prevented an accurate determination of the layer thickness. However, results on island-free samples indicate that the spectra of Fig. 2(a) correspond to values of $d$ in the range 2-10 $\mathrm{nm}$. Figure 2(b) shows the luminescence intensity at $750 \mathrm{~nm}$ as a function of silicon layer thickness for such an island-free sample. The luminescence signal rises rapidly to a peak at $d \approx 2.5 \mathrm{~nm}$, then falls more gradually and becomes negligible for $d>8 \mathrm{~nm}$. The smooth curve shows the calculated fraction of pump light absorbed in the silicon layer. The relative efficiency, given by the ratio of luminescence to $a b-$ sorption, is indicated by the open circles of Fig. 2(b) and is a monotonically decreasing function of $d$.

The well-characterized geometry of these confined silicon strūctures permits a reasonably accurate determination of the radiative quantum efficiency $(\mathrm{QE})$. Assuming that red photons are emitted isotropically into the oxide and refract at the oxide-air interface, and accounting for the collected solid angle, monochromator throughput, and detector quantum efficiency, the $Q E$ of a $2 \mathrm{~nm}$ layer is $\sim 10^{-5}$. If one instead assumes that emission is isotropic in the silicon layer $\left(n_{\mathrm{Si}}=3.8\right)$, then the $\mathrm{QE}$ is $\sim 10^{-4}$, since the emission solid angle seen by the imaging lens is much smaller. In either case, the $\mathrm{QE}$ is $2-4$ orders of magnitude smaller than the $\sim 5 \%$ reported for oxide-terminated silicon nanocrystals at room temperature. ${ }^{17}$

The effect of several thermal treatments on the $Q E$ of samples with variable-thickness wells was investigated. After each treatment the sample was probed at several positions along the taper and spectra taken at the positions giving maximum luminescence were compared. This permitted changes in surface states to be studied independently of $d$. 


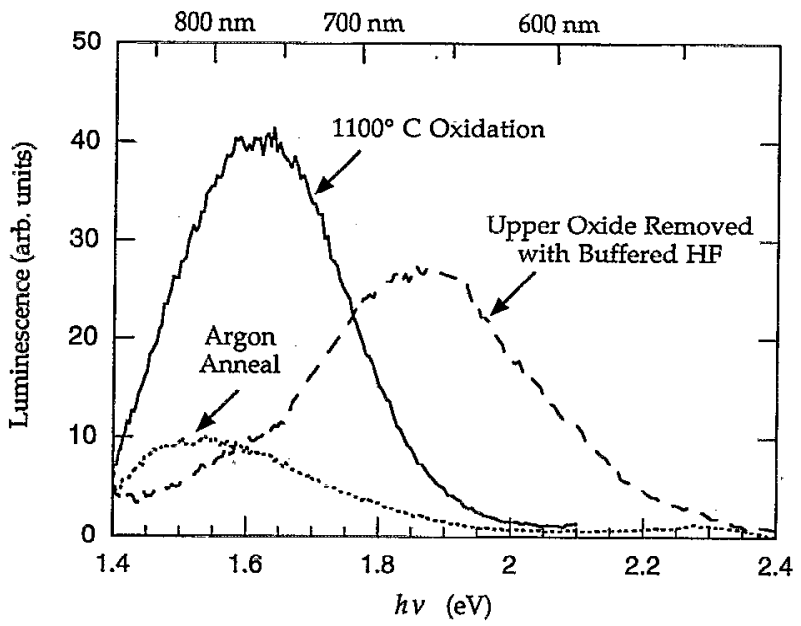

FIG. 3. Luminescence spectra taken following $1100^{\circ} \mathrm{C}$ oxidation, $1100^{\circ} \mathrm{C}$ Ar anneal, and treatment of the upper oxide layer with buffered HF. The spectra were recorded at the position along the taper giving greatest luminescence; spectra taken at different positions had the same shape but lower intensity. Removal of the upper oxide produced a $0.3 \mathrm{eV}$ blue shift.

The treatments included dry oxidation at $800^{\circ} \mathrm{C}$, hightemperature $\left(1100^{\circ} \mathrm{C}\right)$ anneal in $\mathrm{Ar}$, $\sim 400^{\circ} \mathrm{C}$ anneal in steam, and low-temperature $\left(400^{\circ} \mathrm{C}\right.$ ) anneal in $\mathrm{H}_{2} / \mathrm{N}_{2}$. None improved the $\mathrm{QE}$ compared to samples rapidly withdrawn from $1100^{\circ} \mathrm{C}, 1 \mathrm{~atm} . \mathrm{O}_{2}$, and the first three produced significant loss of luminescence signal. A 30-min Ar anneal was found to lower light levels by about an order of magnitude and to produce a slight red shift, as seen in Fig. 3. Lowtemperature oxide growth and steam treatment each caused a $\sim 10 \times$ loss in luminescence, but no discernible spectral shift. Annealing in $\mathrm{H}_{2} / \mathrm{N}_{2}$ restored the luminescence level in a sample that had been oxidized at $800^{\circ} \mathrm{C}$ to that obtained with $1100^{\circ} \mathrm{C}$ oxidation. Finally, the upper oxide layer was removed with $\mathrm{pH}$-buffered $\mathrm{HF}$. This caused a $\sim 0.3 \mathrm{eV}$ blue shift of the luminescence peak and preserved the $\mathrm{QE}$ of the $1100^{\circ} \mathrm{C}$ oxide (Fig. 3).

\section{DISCUSSION}

The fact that no luminescence was observed until the silicon layer thinned below $8 \mathrm{~nm}$ unambiguously identifies quantum confinement in the silicon layer as an essential condition for visible luminescence. Although significant variations in $d$ occur on the micrometer (and probably submicrometer) scale, the silicon behaves optically as a thin layer of smoothly varying mean thickness and the TEM photograph revealed an essentially two-dimensional geometry. The crucial question concerns the very low quantum efficiency of layers compared to nanocrystals.

The essential difference between 0-D nanocrystals and 2-D layers is the ability of photoinjected electrons and holes to diffuse in the layers. If the time for electrons or holes to diffuse to and become captured at a nonradiative midgap interface trap is short compared to the radiative lifetime, luminescence will be quenched. The density of interface traps at the silicon/buried oxide interface in these SIMOX wafers is $D_{\mathrm{it}} \approx 10^{11} \mathrm{~cm}^{-2} \mathrm{eV}^{-1}$. ${ }^{18}$ This is approximately the density of interface states observed in MOS capacitors. In a simple quasi-3-D model of carrier capture by traps, the capture rate, $\tau^{-1}$, is given by the product of the areal trapping probability and the rate at which carriers encounter the interfaces, $\tau^{-1}=\sigma D_{i t} E_{g} \nu / 2 d$, where $\sigma$ is the capture cross section, $E_{g}$ is the gap energy, and $\nu$ is the carrier (thermal) velocity. Cross sections for electrons (holes) are of order $10^{-14}\left(10^{-16}\right) \mathrm{cm}^{-2}$, ${ }^{19}$ giving capture times, $\tau$, of order $10 \mathrm{ps}$ ( $1 \mathrm{~ns})$ at room temperature. Radiative recombination times, however, are expected to be long. Observed lifetimes for nanocrystals are $\sim 50 \mu$ s at $293 \mathrm{~K}$ with $5 \% \mathrm{QE},{ }^{17}$ implying a $1 \mathrm{~ms}$ radiative lifetime for excitonic decay. A $1 \mathrm{~ms}$ radiative lifetime and $0.01-1$ ns trapping time would predict a $\mathrm{QE}$ of $\sim 10^{-8}-10^{-6}$, somewhat lower than the observed value but consistent with a model in which carrier diffusion is reduced by interface roughness.

Interface roughness and variations in $d$ produce potential fluctuations that serve as barriers to the motion of carriers in the layer. The confinement energy, $E$, depends inversely on the well width as $E \propto d^{\cdots n}$, where $n=2$ for a simple envelopefunction calculation, and $n=1.39$ for a more detailed calculation for nanocrystals and wires. ${ }^{20}$ The inverse dependence means that thickness variations of a given size, such as a monolayer, cause changes in confinement energy that increase rapidly as $d$ decreases. Taking $n=1.39$, a monolayer variation in $d$ produces a confinement energy shift equal to room-temperature thermal energy at $d=2.6 \mathrm{~nm}$. Thus as the layer thins, fluctuations in $d$ cause increasing barriers to diffusion and hence longer trapping times.

The spectral shifts caused by $\mathrm{Ar}$ annealing and lowtemperature oxidation provide clues to the mechanism of light emission from quantum-confined silicon. Argon annealing at $1100^{\circ} \mathrm{C}$ produces flatter $\mathrm{Si} / \mathrm{SiO}_{2}$ interfaces, ${ }^{12}$ and may affect interface states, although $D_{\text {it }}$ for thick oxides grown at $1100^{\circ} \mathrm{C}$ in dry oxygen does not appear to be reduced by annealing. ${ }^{21}$ The observed decrease in Iuminescence can be explained by a flatter interface, which permits carricrs to diffuse more readily to nonradiative traps. The red shift may result from an annealing-induced change in the distribution of interface traps. The lower $\mathrm{QE}$ observed for oxidation at $800^{\circ} \mathrm{C}$ can be explained by the higher $D_{\text {it }}$ produced by lowtemperature oxidation. ${ }^{22}$

The increase in luminescence for low-temperature $\mathrm{H}_{2}$ annealing probably arises from the hydrogen passivation of $P_{b}$ states at the interfaces, which are known to provide nonradiative midgap centers. ${ }^{23}$ However, the $0.3 \mathrm{eV}$ blue shift caused by removal of the upper oxide is more difficult to explain in the strict quantum confinement model. A simple envelope-function computation for the shift in confinement energy caused by replacing one oxide barrier with vacuum gives $<30 \mathrm{meV}$. A more likely scenario is radiative recombination involving interface states on the bydrogenterminated surface. The surface-state model also more readily explains the independence of the luminescence spectrum on well thickness [Fig. 2(a)].

\section{CONCLUSIONS}

In summary, photoluminescence was observed from crystal silicon layers between device-quality oxide in a broad red peak for $d \$ 8 \mathrm{~nm}$ with monotonically increasing effi- 
ciency as $d$ decreased and a spectrum that was independent of $d$. A low quantum efficiency was measured $\left(<10^{-4}\right)$ and most likely results from diffusion of carriers to nonradiative interface traps. The problem of diffusion to nonradiative traps is present in all structures confined in fewer than three dimensions and poses an obstacle to efficient electroluminescence in silicon. Post-oxidation annealing in Ar lowered photoluminescence, probably by producing a flatter $\mathrm{Si} / \mathrm{SiO}_{2}$ interface and enhanced carrier diffusion. Removal of the upper oxide layer with $p \mathrm{H}$-buffered $\mathrm{HF}$ produced a $0.3 \mathrm{eV}$ blue shift of the luminescence, which strongly suggests the role of interface states in the radiative recombination of electronhole pairs in quantum confined silicon.

\section{ACKNOWLEDGMENTS}

P. N. S. gratefully acknowledges the support of the NIST-NRC Postdoctoral Research Associate Program.

${ }^{1}$ L. T. Canham, Appl. Phys. Lett. 57, 1046 (1990).

${ }^{2}$ F. Koch, V. Petrova-Koch, T. Muschik, A. Nikolov, and V. Gavrilenko, Mater. Res. Soc. Symp. Proc. 283, 197 (1993); F. Koch, V. Petrova-Koch, and T. Muschik, J. Lumin. 57, 271 (1993).

${ }^{3}$ R. P. Vasquez, R. W. Fathauer, T. George, A. Ksendzov, and T. L. Lin, Appl. Phys. Lett. 60, 1004 (1992).

${ }^{4}$ P. Deák, M. Rosenbauer, M. Stutzmann, J. Weber, and M. S. Brandt, Phys. Rev. Lett. 69, 2531 (1992).

${ }^{5}$ S. L. Friedman, M. A. Marcus, D. L. Adler, Y.-H. Xie,-T. D. Harris, and P. H. Citrin, Appl. Phys. Lett. 62, 1934 (1993).

${ }^{6}$ R. Tsu, H. Shen, and M. Dutta, AppL. Phys. Lett. 60, 112 (1992)

${ }^{7}$ P. D. J. Calcott, K. J. Nash, L. T. Canham, M. J. Kane, and D. Brumhead, J. Lumin. 57, 275 (1993).

${ }^{8}$ R. Williams, Phys. Rev. A 140, 569 (1965).
${ }^{9}$ P. O. Hahn and M. Henzler, J. Vac. Sci. Technol. A 2, 574 (1984).

${ }^{10}$ SIMOX (Separation by IMplantation of OXygen) is prepared from a standard silicon substrate by a high-density, high-energy oxygen implant $\left(10^{18}\right.$ $\mathrm{cm}^{-2}, 190 \mathrm{keV},>600^{\circ} \mathrm{C}$ ) followed by a high-temperature anneal $\left(1320^{\circ} \mathrm{C}, 6 \mathrm{~h}, \mathrm{~N}_{2}\right)$. This yields a slightly silicon-rich $a-\mathrm{SiO}_{2}$ layer between the crystalline substrate and a crystal silicon upper layer of the same orientation. See, e.g., M. K. El-Ghor, S. J. Pennycook, F. Namavar, and N. H. Karam, Appl. Phys. Lett. 57, 156 (1990) and A. Wittkower, M. Guerra, B. Cordts, R. Dolan, and P. Sandow, Nucl. Instrum. Methods B 55, 842 (1991).

${ }^{11}$ The triple-implant wafer also had a lower density of threading dislocations in the silicon layer $\left(<10^{4} \mathrm{~cm}^{-2}\right.$ vs $\left.<5 \times 10^{5} \mathrm{~cm}^{-2}\right)$.

${ }^{12}$ A. Ogura, J. Electrochem. Soc. 138, 807 (1991).

${ }^{13} \mathrm{M}$. Born and E. Wolf, Principles of Optics (Pergamon, Oxford, 1980), p. 627.

${ }^{14}$ G. E. Jellison, Jr. and F. A. Modine, J. Appl. Phys. 53, 3745 (1982).

${ }^{15}$ Handbook of Optical Constants of Solids, edited by E. D. Palik (Academic, Orlando, 1985).

${ }^{16}$ Information about the uniformity of the layer thickness on the micrometer scale was obtained by scanning a HeNe beam focused with a $100 \mathrm{X}$ microscope objective (N.A. $=0.9$, spot size $\sim 0.9 \mu \mathrm{m}$ ) across the sample at positions for which $d<5 \mathrm{~nm}$ and recording reflectivity vs position over a $\sim 25 \mu \mathrm{m}$ range. Calculated reflectivity changes are linear with layer thickness variation for $d<5 \mathrm{~nm}$, from which a thickness spread of $\sim 1.5 \mathrm{~nm}$ peak-to-peak was estimated.

${ }^{17}$ K. A. Littau, P. J. Szajowski, A. J. Muller, A. R. Kortan, and L. E. Brus, J. Phys. Chem. 97, 1224 (1993); W. L. Wilson, P. F. Szajowski, and L. E. Brus, Science 262, 1242 (1993); L. Brus, J. Phys. Chem. 98, 3575 (1994).

${ }^{18} \mathrm{~A}$. Wittkower (private communication).

${ }^{19}$ E. H. Nicollian and J. R. Brews, MOS (Metal Oxide Semiconductor) Physics and Technology (Wiley, New York; 1982), p. 317.

${ }^{20}$ C. Delerue, G. Allan, and M. Lannoo, Phys. Rev. B 48, 11 (1993).

${ }^{21}$ K. Hofmann and M. Schulz, J. Electrochem. Soc. 132, 2201 (1985).

${ }^{22}$ R. R. Razouk and B. E. Deal, J. Electrochem. Soc. 126, 1573 (1979).

${ }^{23}$ F. J. Himpsel, F. R. McFeely, A. Taleb-Ibrahimi, J. A. Yarmoff, and G. Hollinger, Phys. Rev. B 38, 6084 (1988). 